\title{
Simultaneous septic arthrodesis of the tibiotalar and subtalar joints with the llizarov external fixator-an analysis of 13 patients
}

\author{
Charlotte Cibura ${ }^{1}$ (D) Sebastian Lotzien ${ }^{1} \cdot$ Emre Yilmaz $^{1} \cdot$ Hinnerk Baecker $^{1} \cdot$ Thomas Armin Schildhauer $^{1}$. \\ Jan Gessmann ${ }^{1}$
}

Received: 3 May 2021 / Accepted: 16 July 2021 / Published online: 29 July 2021

(c) The Author(s) 2021

\begin{abstract}
Purpose Treatment of joint destruction of the tibiotalar and subtalar joints caused by acute or chronic infections in compromised hosts is a challenging problem. In these cases, simultaneous septic arthrodesis with the use of the Ilizarov external fixator represents a possible alternative to amputation. This case series presents the results and complications of patients with acute or chronic infection of the tibiotalar and subtalar joints.

Methods Between 2005 and 2015, 13 patients with acute or chronic infections were treated by simultaneous single-stage debridement/arthrodesis of the tibiotalar and subtalar joints. In seven patients, there was a florid infection with fistula formation and soft tissue defects, and in six patients, there was chronic osteomyelitis with closed soft tissue. In addition to the demographic data, the time spent in the fixator, the major and minor complications and the endpoint of consolidation were reviewed.

Results The mean time spent in the fixator was 18 ( $\min 15$, max 26) weeks. The mean follow-up time for nine patients was 100 ( $\min 3, \max 341$ ) weeks. Complete osseous consolidation of both the tibiotalar and subtalar joints was achieved in 10 patients (77\%). In three (23\%) patients, there was complete consolidation of one of the joints and partial consolidation of the other joint.

Conclusion The Ilizarov external fixator allows for simultaneous arthrodesis of the tibiotalar and subtalar joints in septic joint destruction. However, the healing rates are below the rates reported in the literature for isolated tibiotalar or tibiocalcaneal arthrodesis in comparable clinical situations.
\end{abstract}

Keywords Ilizarov fixator $\cdot$ Septic arthrodesis $\cdot$ Simultaneous arthrodesis $\cdot$ Subtalar joint $\cdot$ Tibiotalar joint

$\begin{array}{ll}\text { Abbreviations } \\ \text { CT } & \text { Computed tomography } \\ \text { COM } & \text { Chronic osteomyelitis } \\ \text { DM } & \text { Diabetes mellitus } \\ \text { HTN } & \text { Hypertension } \\ \text { PAOD } & \text { Peripheral arterial occlusive disease } \\ \text { PNP } & \text { Polyneuropathy } \\ \text { VAC } & \text { Vacuum-assisted closure }\end{array}$

Charlotte Cibura

charlotte.cibura@bergmannsheil.de; charlottecibura@gmx.de

1 Department of Trauma Surgery and General Surgery, BG University Hospital Bergmannsheil, Ruhr University Bochum, Bürkle-de-la-Camp-Platz 1, 44789 Bochum, Germany

\section{Background}

Since the introduction of compression arthrodesis by Charnley in 1951, several different surgical procedures have been described as treatment options for various causes of ankle destruction [1]. Internal procedures such as the use of plates $[2,3]$ or screws [4] as well as intramedullary fixation [5, 6], arthroscopic fusion $[6,7]$ or external stabilization using external fixators can be used to achieve solid arthrodesis [1, $8-11]$. However, these procedures are mainly used in aseptic patients, and the treatment of diffuse septic ankle destruction, especially in compromised hosts, remains a challenge.

Although inflammatory arthritis has been described previously $[12,13]$, the main causes of septic destruction are posttraumatic postoperative complications and diabetic foot syndrome $[12,14,15]$. The primary treatment goal is infection control and limb preservation with pain-free weightbearing capacity. However, the vast majority of cases are 
additionally complicated by soft tissue defects, local infections, extensive scar tissue, polyneuropathy (PNP), a resistant bacterial spectrum or axial malalignments (varus/ valgus). In addition, patients often suffer from other risk factors, such as alcohol or nicotine abuse, polytoxicomania, diabetes mellitus (DM) or obesity [12,16-18]. Internal treatment options are limited in such cases [12, 19].

The Ilizarov ring fixator is an external system that provides dynamic axial fixation with high stability by introducing transfixing wires and screws outside of the infected tissue $[18,19]$. In the literature, there are only a few studies on the treatment of septic arthrodesis with the Ilizarov fixator [19-22]. Most studies have a mixed aseptic/septic patient population [10, 12-16, 18, 23, 24]. Furthermore, most studies have focused on tibiotalar arthrodesis. The purpose of this study was to evaluate the use of the Ilizarov external fixator in patients with acute or chronic infections of the tibiotalar and subtalar joints.

Particular attention was given to consolidation as well as minor and major complications. Does the Ilizarov fixator achieve good results for simultaneous septic arthrodesis of the tibiotalar and subtalar joints? Are these results comparable to those described in the literature of isolated arthrodesis in only one joint?

\section{Patients and methods}

We performed a single-center, retrospective study including all simultaneous tibiotalar and subtalar joint arthrodesis procedures performed using the Ilizarov external fixator at the authors' institution from $01 / 2005$ to $12 / 2015$. To capture all patients with these criteria and their demographic data, a keyword analysis of all digitized files was performed by the author of this study (CC). The demographic data included the age and sex of the patients, associated relevant concomitant diseases, the source of the infection, time spent in the fixator, the complications and bony consolidation. The demographic data were recorded to provide a precise understanding of the complex patient population and are presented in Table 1. Following the work of Katsenis, complications were considered to be minor when conservative therapy was sufficient and major when surgical revision was required [25]. The data were collected anonymously using Microsoft Excel () Version 14.7.7. The exclusion criteria were as follows: (1) patients with isolated arthrodesis of the tibiotalar or subtalar joint, (2) tibiocalcaneal arthrodesis or (3) aseptic findings.

This study included a total of 13 patients ( 8 men and 5 women), with a mean age of 53 ( $\min 27-\max 74)$ years. Seven patients were classified as having chronic osteomyelitis (COM), and six patients suffered from a florid, fulminant infection with joint destruction (Case Figs. 1 and 2). All patients also showed poor soft tissue conditions characterized by pronounced scar tissue, fistula formation, soft tissue abscess and/or necrosis of the skin. The majority of patients (7/13, 54\%) suffered from posttraumatic arthrosis. Other findings included Charcot arthropathies, ganglion excisions, filling of a talar cyst, and unclear arthritic destruction (Table 1). In five patients, pathogens were detected by pre- and intraoperative smears and soft tissue samples. One patient had a mixed infection of Escherichia coli and Enterococcus faecalis (Table 2). Concomitant diseases were found in eight patients, of whom six suffered from relevant diseases such as DM, PNP, alcohol abuse and/or peripheral arterial occlusive disease (PAOD). Another risk factor was nicotine abuse, which was observed in two patients.

All patients were referred to us from another hospital after undergoing four operations on average (min 2-max 6). As part of the surgical treatment, all patients underwent resection arthroplasty of the tibiotalar and subtalar joints using medial and lateral approaches. Extensive debridement was performed by removing all infected cartilage, bone and soft tissue, including resection of the medial and lateral malleolus. The subtalar joint was resected by extending the lateral approach distally. The arthrodesis was positioned at 5 degrees of hindfoot valgus and 15 degrees of external rotation. Temporary fixation was carried out using $3 \times 2.5 \mathrm{~mm} \mathrm{k}$-wires placed from distal to proximal through the calcaneus and tibia.

After medial and lateral wound closure, the Ilizarov frame was applied. The frames were preassembled individually preoperatively in terms of ring size and strut length and then sterilized so that a time-consuming construction did not have to be carried out intraoperatively. The frame consisted of at least four, sometimes five, ring planes, each with two crossed strained $1.8 \mathrm{~mm}$ steel wires per ring. The rings were placed at the level of the proximal and distal tibia, talus and calcaneus (a half-ring in the area of the calcaneus). The wires were tensioned up to $110 \mathrm{~kg}(1080 \mathrm{~N})$ using the tensioning device. In addition, one or two half pins were attached for further stabilization in the area of the tibia shaft. The midfoot was transfixed with wires placed through the metatarsals (Fig. 3).

The ring system enabled compression of both the tibiotalar and subtalar joints (Case Fig. 4). In cases of soft tissue defects, a temporary wound vacuum-assisted closure (VAC) was installed, and this method was used in four patients. Two of these patients were successfully treated by this procedure with subsequent mesh graft coverage. In the other two patients, secondary wound healing was achieved by wound dressings. All patients initially received a calculated dose of antibiotics in accordance with the resistogram for a total of six weeks. The patients were allowed to perform full axial loading during the time spent wearing the fixator. To avoid the development of a pointed foot or 


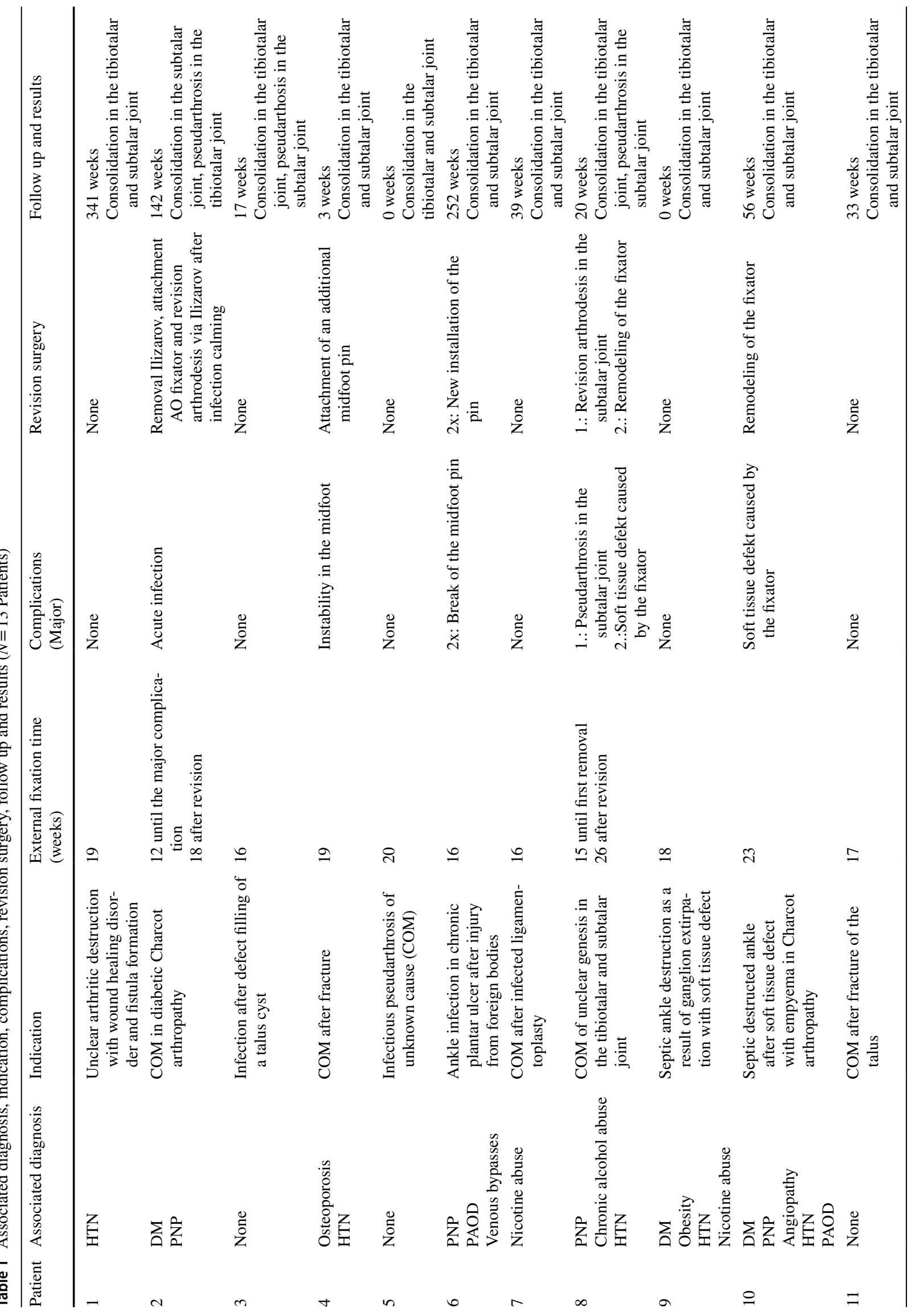



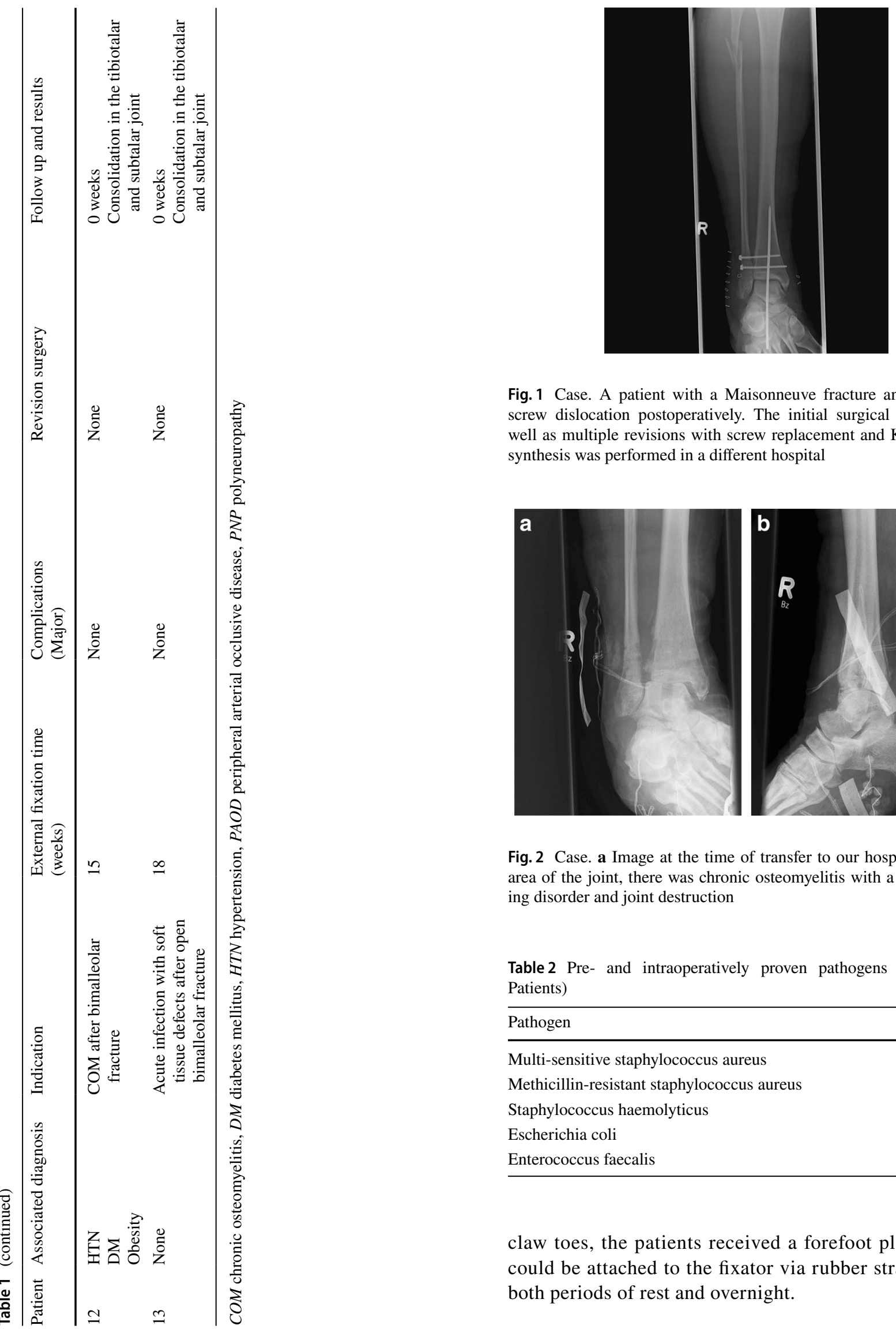

Fig. 1 Case. A patient with a Maisonneuve fracture and secondary screw dislocation postoperatively. The initial surgical treatment as well as multiple revisions with screw replacement and K-wire osteosynthesis was performed in a different hospital

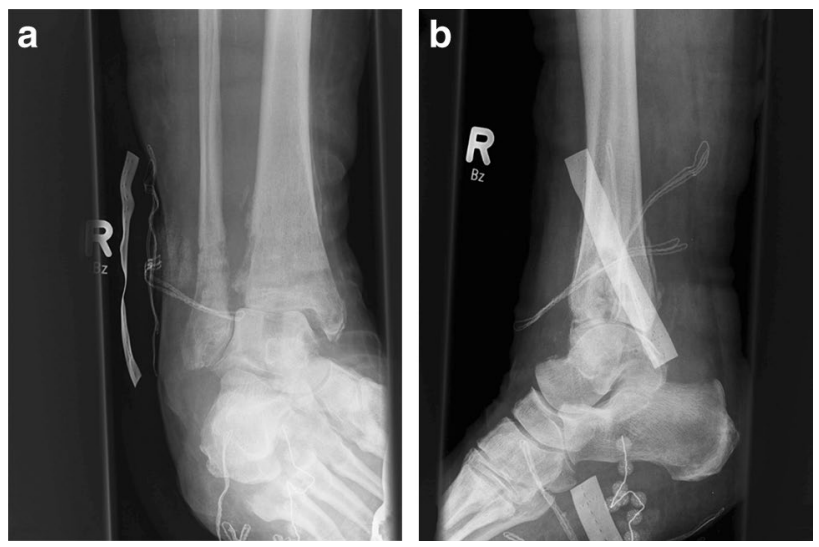

Fig. 2 Case. a Image at the time of transfer to our hospital. b In the area of the joint, there was chronic osteomyelitis with a wound healing disorder and joint destruction

Table 2 Pre- and intraoperatively proven pathogens $(N=6$ in 5 Patients)

Pathogen

Patients

Multi-sensitive staphylococcus aureus

2

Methicillin-resistant staphylococcus aureus

Staphylococcus haemolyticus

1

Escherichia coli

1

Enterococcus faecalis

claw toes, the patients received a forefoot plate, which could be attached to the fixator via rubber straps during both periods of rest and overnight. 

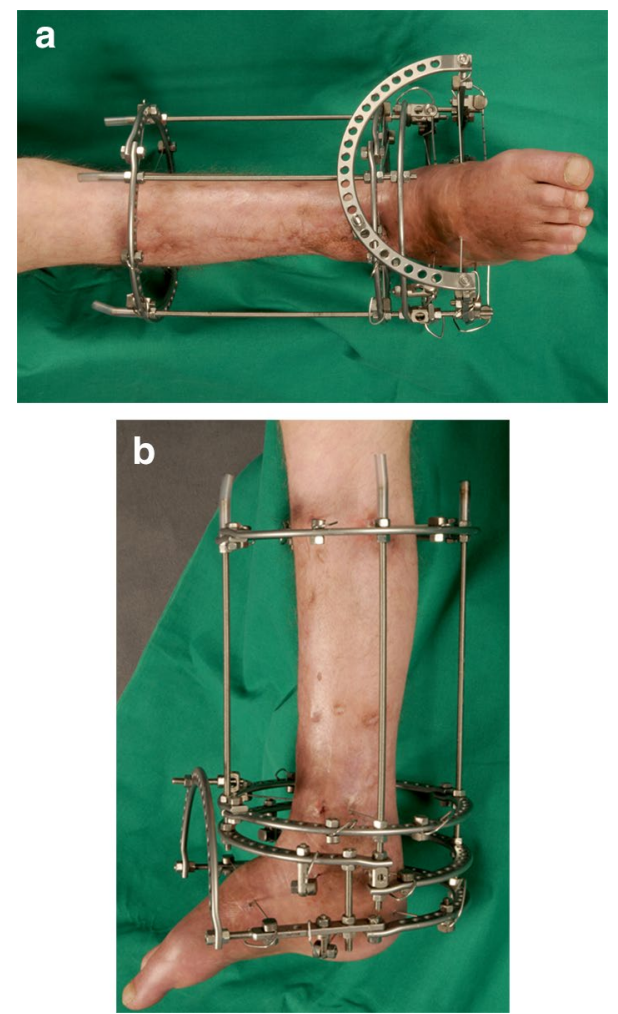

Fig. 3 Clinical picture of an attached Ilizarov fixator for simultaneous arthrodesis
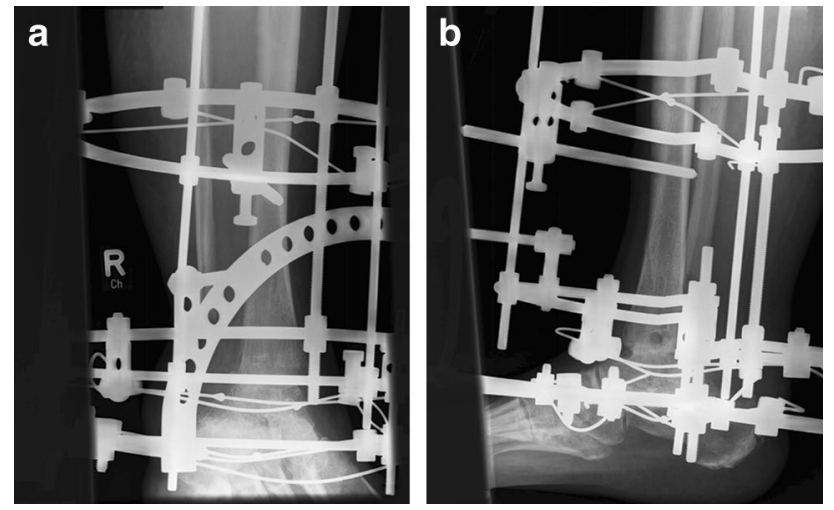

Fig. 4 Case. a Image of the attached Ilizarov fixator for simultaneous arthrodesis in the tibiotalar and subtalar joints. $\mathbf{b}$ The image was taken seven weeks after surgery in our hospital

After the inpatient stay, biweekly tensioning of the fixator for compression arthrodesis was applied during the consultation. (The fixator was compressed by $2 \mathrm{~mm}$ each time.) Radiolographical control was performed every four weeks. After removal of the fixator, the mean clinical/radiological follow-up period was $100(\min 3, \max 341)$ weeks for a total of nine patients. Four patients were lost to further follow-up after removal of the fixator due to an invalid mailing address.
Bony union was confirmed clinically and radiographically. The clinical signs included no motion at the fusion site. Union was defined radiographically using plane radiographs in four projections or computed tomography (CT) scans. In 6 patients, CT was performed to verify consolidation. Among the remaining 7 patients, there was clear consolidation on the X-ray.

\section{Results}

The mean time spent in the fixator was 18 ( $\min 15-\max 26)$ weeks. Bony arthrodesis of both the tibiotalar and subtalar joints was primarily achieved in 10 out of 13 patients (77\%) (Case Fig. 5). In three (23\%) patients, complete consolidation of one of the joints and partial consolidation of the other joint were found. For these patients, a conservative procedure was carried out by using carbon orthotic adaptation.

Recurrent infections did not occur during the follow-up period of a mean of $100(\min 3, \max 341)$ weeks in nine patients. During treatment with the fixator, local pin infections occurred in all patients, but all patients could be treated locally with pin care and, if necessary, stab incision and oral antibiotics. Major procedural complications occurred in a total of seven ankles in five patients (Table 1). In patient two, a severe infection occurred after 12 weeks spent in the fixator, and removal of the fixator was necessary. Extensive debridement and installation of an $\mathrm{AO}$ fixator were performed. After infection control was achieved, revision arthrodesis via the Ilizarov fixator was performed ( 2 months after the removal of the first Ilizarov fixator). After another 18 weeks spent in the fixator, the Ilizarov fixator was removed. Consolidation of the tibiotalar joint could not be achieved, and carbon orthosis had to be adjusted. Another surgery was rejected by the patient.
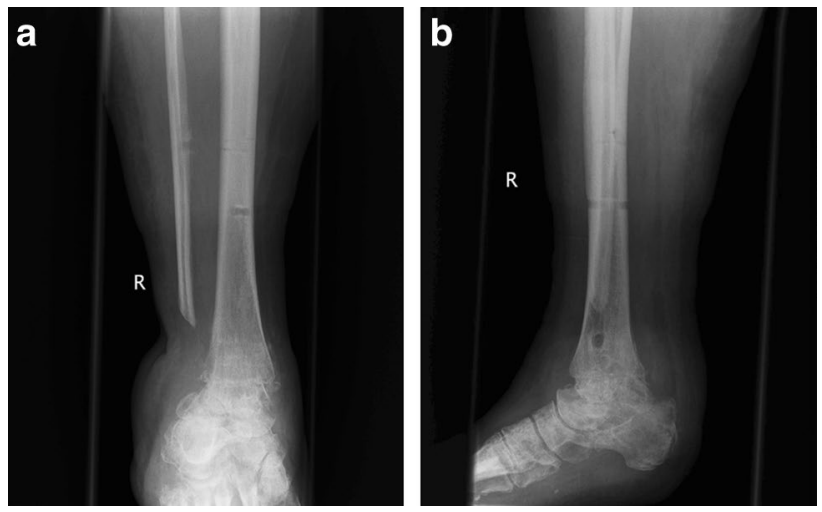

Fig. 5 Case. a After 19 weeks spent in the fixator, the fixator was removed. b There was bony consolidation in the tibiotalar and subtalar joints 
In patient four, there was instability in the forefoot and an additional midfoot pin had to be inserted eight days after fixation. The time spent in the fixator was not extended, and after 19 weeks, consolidation of both ankle joints was achieved.

In patient six, a break in the midfoot pin occurred twice, and thus, a new installation was necessary. This also did not extend the time spent in the fixator, and after 16 weeks, consolidation of both joints occurred.

In patient eight, there was a soft tissue defect caused by the fixator, which is why the fixator was rebuilt (after 27 days). The fixator was removed after 15 weeks. Bony consolidation of the subtalar joint could not be achieved. Therefore, revision arthrodesis was performed, including reinstallation of the Ilizarov fixator and cancellous bone grafting. After another 26 weeks in the fixator, no complete bony consolidation of the subtalar joint could be achieved. Carbon orthosis had to be adjusted. The total duration of treatment was 60 weeks. In patient 10, there was also a soft tissue defect caused by the fixator, which is why the fixator was rebuilt. After 23 weeks, consolidation of both joints was achieved.

\section{Discussion}

Septic arthrodesis represents a therapeutic option that could prevent limb amputation in patients with septic ankle joint destruction or COM with concomitant soft tissue defects/ infections and additional risk factors such as nicotine abuse, DM or polytoxicomania $[8,13,19,22,26]$. However, to achieve arthrodesis in a setting of acute infection, biomechanical and biological preconditions must be met. Dynamic axial fixation with high stability against bending, shear and torsional forces, without introducing foreign material, is warranted in these cases. In addition, despite the external fixator, it is possible to treat existing soft tissue defects with, for example, VAC therapy at the same time.

The Ilizarov fixator is an available tool that exhibits all of these characteristics $[10,14,16,19]$. By introducing transfixing wires outside of the infected tissue, stability can be achieved under poor bone and/or soft tissue conditions. With continuous compression in the area of the arthrodesis zone, which is achieved by a possible full load and by regular retightening of the fixator, bone healing is promoted [19].

Some studies of tibiotalar or tibiocalcaneal arthrodesis using the Ilizarov fixator can be found in the literature. However, the majority analysed aseptic or mixed septic/aseptic patients [10,12-14, 16, 18, 23, 24, 27]. Healing rates in patients with acute infection or chronic osteomyelitis vary between 75 and $100 \%$. In all of these studies, as was the case in this study, a one-step procedure was performed. Rochman et al. used a two-step approach with debridement and antibiotic chain insertion first. In five out of seven patients (71\%), consolidation was reported [15]. Studies using mainly or only a septic patient population are rare $[8,19,20,22]$. Gessmann et al. studied a population of 37 patients with septic ankle joint destruction (20 with a florid infection) and achieved primary arthrodesis in 32 patients (86.5\%) [19]. Saltzmann et al. studied eight patients with COM who underwent arthrodesis using the Ilizarov fixator [22]. In $87.5 \%$ of the patients, consolidation and calming of the infection were achieved. One patient had to undergo amputation of the lower leg. Kollig et al. and Huang et al. reported $93 \%$ and $100 \%$ consolidation rates, respectively. However, they used a hybrid fixator, not a ring fixator $[8$, 20]. Although a hybrid fixator is not as bulky or expansive as an Ilizarov ring fixator, it has the disadvantage that a full axial load cannot be applied; thus, early mobilization cannot be achieved. Therefore, complete load removal of the leg during the healing period under constant thrombosis prophylaxis is necessary.

The success rate of $77 \%$ for the septic patient population found in our study is lower than the rates found in the cited studies. However, in our study, with similar patients, the tibiotalar and subtalar joints were simultaneously addressed. Only Saltzman et al. reported simultaneous treatment of both joints in four septic patients, and simultaneous bony arthrodesis was reported in three out of four patients. In all of the other studies mentioned, either tibiotalar or tibiocalcaneal arthrodesis was performed [10, 12-16, 18, 19, 23, 24, 27].

The rate of major procedural complications of $46 \%$ also appeared to be relatively high in our study, although the data in the literature vary regarding this rate. Gessmann et al. reported a major complication rate of $16 \%$ with three pin breakages and three deep pin infections. Deep pin infections did not occur in our patients, but breakage of the pin did occur in two patients. Saltzmann et al. also reported a pin break. However, in a total of eight patients, a pin break was the only major complication described. A tibial pin was reported to be broken [22]. Johnson et al. reported the need for premature fixator removal due to intolerance of the fixator. No other major complications were reported in a total of six patients [10]. Fragomen et al., Salem et al. and Zarutsky et al. reported a similar incidence of major procedural complication rates in mixed septic/aseptic patients, with $32 \%$, $36 \%$, and $51 \%$ complication rates, respectively, compared to the rate found in our study, although it was not a purely septic patient population. However, the time spent in the fixator was longer than in other studies, an average of 25 weeks (Fragomen et al.) and 27.7 weeks (Salem et al.), and in our study (18 weeks), which can be explained by simultaneous segmental transport of the fixator $[12,16]$.

Other complications have been reported, including tibial stress fractures, pseudarthroses, pseudarthroses with deformities greater than 10 degrees, fulminant infections, 
tibial nerve neurapraxia and necrosis of the talus $[12,16]$. In addition to pin breaks and forefoot instability, our study also found fixator-related soft tissue defects $(2 \mathrm{x})$, pseudarthrosis $(1 \mathrm{x})$ and one fulminant infection. Zarutsky et al. reported that major complications occurred more frequently in patients with side effects such as DM, Charcot arthropathy, or septic fusion [18]. Other studies also described an increased complication rate in patients with difficult soft tissue conditions, circulatory disorders, and nicotine and alcohol abuse [12, 28, 29]. This result was confirmed in our study. Four out of the five patients with major complications had DM, PAOD, Charcot arthropathy, nicotine consumption and/or alcohol abuse.

This study had several limitations. The study sample of 13 patients was small, and the study had a retrospective design. Furthermore, a large number of patients were lost to follow-up. We treat patients from all over the country, which is why regular follow-up is not always possible.

Due to the small number of patients, this work cannot be the basis of a standardized therapy recommendation. This would require further studies with a larger patient population. In addition, comparable studies with simultaneous arthrodesis of the tibiotalar and subtalar joints are not available. There was also no long-term clinical follow-up for the evaluation of infection-free patients or subjective patient satisfaction. However, the results presented here show that this method represents an alternative to amputation for selected patients. However, clinical decisions will require a detailed explanation of the long and complex treatment times as well as the procedural complications on a case-by-case basis.

\section{Conclusion}

The Ilizarov fixator allows for simultaneous arthrodesis of the tibiotalar and subtalar joints in septic joint destruction. However, the complication rates of this procedure are high, and the healing rates are lower than the rates for isolated tibiotalar or tibiocalcaneal arthrodesis in comparable clinical situations, as described in the literature. More research with a larger patient sample needs to be performed to confirm our results.

Authors'contributions All authors contributed to the study conception and design. Data collection and analysis were performed by CC, SL, $\mathrm{EY}, \mathrm{HB}$, TS and JG. The first draft of the manuscript was written by $\mathrm{CC}$, and all authors commented on previous versions of the manuscript. All authors read and approved the final manuscript.

Funding Open Access funding enabled and organized by Projekt DEAL

Data availability All of the data are electronically available.

\section{Declarations}

Conflict of interest Charlotte Cibura, Sebastian Lotzien, Emre Yilmaz, Hinnerk Baecker, Thomas Schildhauer and Jan Gessmann confirm that there is no conflict of interest.

Ethical approval There is a positive statement of the Institutional Review Board for this work (registration number: 18-6582-BR).

Consent to participate All patients agreed to participate in the study.

Consent for publication All authors have approved the publication.

Open Access This article is licensed under a Creative Commons Attribution 4.0 International License, which permits use, sharing, adaptation, distribution and reproduction in any medium or format, as long as you give appropriate credit to the original author(s) and the source, provide a link to the Creative Commons licence, and indicate if changes were made. The images or other third party material in this article are included in the article's Creative Commons licence, unless indicated otherwise in a credit line to the material. If material is not included in the article's Creative Commons licence and your intended use is not permitted by statutory regulation or exceeds the permitted use, you will need to obtain permission directly from the copyright holder. To view a copy of this licence, visit http://creativecommons.org/licenses/by/4.0/.

\section{References}

1. Charnley J (1951) Compression arthrodesis of the ankle and shoulder. J Bone Joint Surg [Br] 33:180-191

2. Braly WG, Baker JK, Tullos HS (1994) Arthrodesis of the ankle with lateral plating. Foot Ankle Int 15:649-653. https://doi.org/ 10.1177/107110079401501204

3. Rowan R, Davey KJ (1999) Ankle arthrodesis using an anterior AO T plate. J Bone Joint Surg [Br] 81:113-116. https://doi.org/ 10.1302/0301-620x.81b1.8999

4. Grass R, Rammelt S, Endres T, Zwipp H (2005) Reorientierende Arthrodese des oberen Sprunggelenks in der 4-SchraubenTechnik [Reorientational arthrodesis of the ankle joint using four screws]. Orthopade 34:1209-1215. https://doi.org/10.1007/ s00132-005-0863-0

5. Grass R, Rammelt S, Heineck J, Zwipp H (2005) Die Rückfussarthrodese durch retrograde Marknagelung [Hindfoot arthrodesis resulting from retrograde medullary pinning]. Orthopade 34:1238-1244. https://doi.org/10.1007/s00132-005-0865-y

6. Cameron SE, Ullrich P (2000) Arthroscopic arthrodesis of the ankle joint. Arthroscopy 16:21-26. https://doi.org/10.1016/s07498063(00)90123-3

7. Jerosch J (2005) Arthroscopic in situ arthrodesis of the upper ankle. Orthopade 34:1198-1208. https://doi.org/10.1007/ s00132-005-0862-1

8. Kollig E, Esenwein SA, Muhr G, Kutscha-Lissberg F (2003) Fusion of the septic ankle: experience with 15 cases using hybrid external fixation. J Trauma 55:685-691. https://doi.org/10.1097/ 01.ta.0000051933.83342.e4

9. Berman AT, Bosacco SJ, Parks BG, Israelite CL, Austin DK, Farrell ED, Quartararo LG (1999) Compression arthrodesis of the ankle by triangular external fixation: biomechanical and clinical evaluation. Orthopaedics 22:1129-1134

10. Johnson EE, Weltmer J, Lian GJ, Cracchiolo A 3rd (1992) Ilizarov ankle arthrodesis. Clin Orthop Relat Res 280:160-169 
11. Kiene J, Schulz AP, Hillbricht S, Jürgens Ch, Paech A (2009) Clinical results of resection arthrodesis by triangular external fixation for posttraumatic arthrosis of the ankle joint in 89 cases. Eur J Med Res 14:25-29. https://doi.org/10.1186/2047-783x-14-1-25

12. Salem KH, Kinzl L, Schmelz A (2006) Ankle arthrodesis using Ilizarov ring fixators: a review of 22 cases. Foot Ankle Int 27:764770. https://doi.org/10.1177/107110070602701002

13. El-Alfy B (2010) Arthrodesis of the ankle joint by Ilizarov external fixator in patients with infection or poor bone stock. Foot Ankle Surg 16:96-100. https://doi.org/10.1016/j.fas.2009.06.004

14. Yanuka M, Krasin E, Goldwirth M, Cohen Z, Otremski I (2000) Ankle arthrodesis using the Ilizarov apparatus: good results in 6 patients. Acta Orthop Scand 71:297-300. https://doi.org/10.1080/ 000164700317411915

15. Rochman R, Jackson Hutson J, Alade O (2008) Tibiocalcaneal arthrodesis using the Ilizarov technique in the presence of bone loss and infection of the talus. Foot Ankle Int 29:1001-1008. https://doi.org/10.3113/fai.2008.1001

16. Fragomen AT, Borst E, Schachter L, Lyman S, Rozbruch SR (2012) Complex ankle arthrodesis using the Ilizarov method yields high rate of fusion. Clin Orthop Relat Res 470:2864-2873. https://doi.org/10.1007/s11999-012-2470-9

17. Rabinovich RV, Haleem AM, Rozbruch SR (2015) Complex ankle arthrodesis: review of the literature. World J Orthop 6:602-613. https://doi.org/10.5312/wjo.v6.i8.602

18. Zarutsky E, Rush SM, Schuberth JM (2005) The use of circular wire external fixation in the treatment of salvage ankle arthrodesis. J Foot Ankle Surg 44:22-31. https://doi.org/10.1053/j.jfas.2004. 11.004

19. Gessmann J, Ozokyay L, Fehmer T, Muhr G, Seybold D (2011) Arthrodesis of the infected ankle joint: results with the Ilizarov external fixator. Z Orthop Unfall 149:212-218. https://doi.org/10. 1055/s-0030-1250360

20. Huang L, Wang S, Teng X, Yang S, Xia Z, Zhao G, Wang T, Wang M (2015) Tibiotalar or tibiocalcaneal arthrodesis using the ilizarov technique in the presence of infected nonunions of ankle joints. Zhonghua Wai Ke Za Zhi 53:405-409
21. Schmidt HG, Hadler D, Gerlach UJ, Schoop R (2005) Principles of OSG arthrodesis in cases of joint infection. Orthopade 34:1216-1228. https://doi.org/10.1007/s00132-005-0870-1

22. Saltzman CL (2005) Salvage of diffuse ankle osteomyelitis by single-stage resection and circumferential frame compression arthrodesis. Iowa Orthop J 25:47-52

23. Hawkins BJ, Langerman RJ, Anger DM, Calhoun JH (1994) The Ilizarov technique in ankle fusion. Clin Orthop Relat Res 303:217-225

24. Kovoor CC, Padmanabhan V, Bhaskar D, George VV, Viswanath $S$ (2009) Ankle fusion for bone loss around the ankle joint using the Ilizarov technique. J Bone Joint Surg Br 91:361-366. https:// doi.org/10.1302/0301-620x.91b3.20935

25. Katsenis D, Bhave A, Paley D, Herzenberg JE (2005) Treatment of malunion and nonunion at the site of an ankle fusion with the Ilizarov apparatus. J Bone Joint Surg Am 87:302-309. https://doi. org/10.2106/jbjs.c.01421

26. Cierny G, Cook WG, Mader JT (1989) Ankle arthrodesis in the presence of ongoing sepsis indications, methods, and results. Orthop Clin North Am 20:709-721

27. Reinke C, Lotzien S, Yilmaz E, Hanusrichter Y, Ull C, Baecker H, Schildhauer TA, Geßmann J (2021) Tibiocalcaneal arthrodesis using the Ilizarov fixator in compromised hosts: an analysis of 19 patients. Arch Orthop Trauma Surg. https://doi.org/10.1007/ s00402-021-03751-0

28. Rogers LC, Bevilacqua NJ, Frykberg RG, Armstrong DG (2007) Predictors of postoperative complications of Ilizarov external ring fixators in the foot and ankle. J Foot Ankle Surg 46:372-375. https://doi.org/10.1053/j.jfas.2007.06.004

29. Wukich DK, Belczyk RJ, Burns PR, Frykberg RG (2008) Complications encountered with circular ring fixation in persons with diabetes mellitus. Foot Ankle Int 29:994-1000. https://doi.org/10. 3113/fai.2008.0994

Publisher's Note Springer Nature remains neutral with regard to jurisdictional claims in published maps and institutional affiliations. 